\title{
Application of PBL Method in the Experimental Teaching of Clinical
}

\section{Pharmacology}

\author{
$\mathrm{He} \mathrm{Li}^{\mathrm{a} \triangle}$, Chunmei Wang ${ }^{\mathrm{b}}$,Chengyi Zhang ${ }^{\mathrm{c}}$, Hongxia Sun ${ }^{\mathrm{d}}$, \\ Jinghui Sun ${ }^{\mathrm{e}^{*}}$ and Jianguang Chen $^{\mathrm{f}^{*}}$ \\ College of Pharmacy, Beihua University, Jilin City, 132013, China \\ aemail: yitonglh@126.com, bemail: 413437244@qq.com,

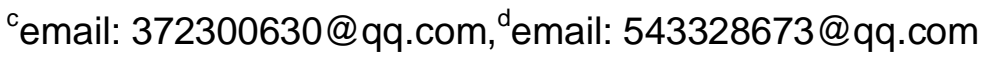 \\ eemail: 893716972@qq.com corresponding author, \\ femail: 644257703@qq.com, corresponding author, \\ ${ }^{\triangle}$ co-first author, ${ }^{*}$ corresponding author
}

Keywords: PBL (Problem-based learning); Clinical pharmacology; Experimental teaching; Quality of teaching

Abstract. Clinical pharmacology is the study of the interaction of drug with the human body and clinical pharmacology experiment is an essential part of clinical pharmacology course. PBL method is problem-centered, closely linked to the course content, and can make students participate in the whole teaching process. In this study, PBL method was applied in the experiment teaching of clinical pharmacology for improving the quality of experiment teaching in clinical pharmacology. The results showed that most of the students believed that the application of PBL in the clinical pharmacology experiment could improve their learning methods, cultivate their innovative thinking, problem-posing, problem-analyzing and problem-solving capacity, language expression and interpersonal communication capacity, strengthen their team assistance spirit, make the relationship between teachers and students more harmonious and the class atmosphere more active, and improve their understanding on the experiment content and their experiment skills significantly, which may lay a foundation for the students' future work in clinical pharmacy.

Clinical pharmacology is the study dealing with the interaction law between drugs and the human body. Contents of clinical pharmacology primarily include pharmacokinetics, pharmacodynamics, the nature and mechanisms of drug adverse reactions, and the law of drug interaction, which are important components of clinical drug trials. Clinical pharmacology experiment is an essential part of clinical pharmacology courses, and through series of clinical pharmacology experiment, students can know well and understand basic knowledge of pharmacokinetics and pharmacodynamics, and basic methods used for the research on pharmacokinetics and pharmacodynamics, which can lay a foundation for their future work in the drug clinical trial and therapeutic drug monitoring ${ }^{[1-3]}$. Especially in the individualized medication and individualized treatment widely concerned, in line with the precision medicine recently declared by National Health and Family Planning Commission and Ministry of Science and Technology of the People's Republic of China, it is even more required that future clinical pharmacists and clinical pharmacy researchers understand the related research thinking and experiment techniques, so that how to improve the teaching quality of clinical pharmacology 
experiment has become an important issue that we educators responsible for the education of clinical pharmacy should consider.

Problem-based learning (PBL) mode is a type of learning based on problems, also known as question type learning, proposed first by Barrows, a neurology professor from the United States, at McMaster University in Canada in 1969, and has now been adopted by many medical colleges and university, and become a teaching mode of medical courses all over the world. In the application of PBL, a problem is focused on and the course content is made associated with the problem, and the students participate in the whole process. The problem is the start of teaching activities and the main thread throughout the teaching process, and also the end of teaching activities. The problem is not only a prerequisite to arouse students ' curiosity, but also a prerequisite for students to understand and absorb the knowledge . During the process of problem solving, students can not only learn the necessary knowledge, but also understand the correct scientific thinking and reasoning methods, and cultivate their self-study capability. In PBL, the course taking a subject as the basis is replaced by a integrated course, the teaching focused on the knowledge is replaced by a teaching focused on students' capacity training, and the traditional classroom teaching is replaced by a method of teacher guidance combined with group discussion, to inspire students' interest in the experimental course, improve their learning initiative, and cultivate their scientific thinking, and innovative, hands-on and the self-study capacities, so that their integrated quality can be improved. Therefore PBL teaching mode is considered to be a bridge linking the theory and practice ${ }^{[4-5]}$.

Due to the reasons described above, teachers at department of clinical pharmacology in our college have made some attempts in the teaching of pharmacology with PBL method based on the teaching reform and practice in our university, and achieved initial results. Here, our thinking and practice in the application of PBL in the experimental teaching of clinical pharmacology are discussed from following aspects.

Objects of Research. Adult education undergraduate students enrolled in clinical pharmacy through the national examination in 2012 were chosen as the object of research and randomly divided into an experimental group and a control group. There was no statistically significant difference in the age, sex and entrance score of students between two groups. Students in two groups had completed the basic medical courses, such as human anatomy, so that they had some basic medical knowledge and abilities, which could lay a good foundation for the PBL teaching.

Design of Clinical Pharmacology Experiment. The problems were centered on throughout the whole process of experimental design, during which the students could improve their learning abilities constantly while they looked for problems, identify problems or solve the problems. Depending on the circumstances, the experimental design was divided into two types: content-specified experiment and self-designed experiment.

Design of content-specified experiment. First of all, the teacher raised several questions for the determination of the experiment objective. In accordance with specific conditions, the teacher could limit the experimental reagents, the species and quantity of experimental animals, experimental equipment and materials, and one or several methods related to the experiment; then the students were asked to refer to the relevant literature and study material, draw up an experimental program; the teacher organized the students to discuss the program, and the experiment was carried out after a experimental design was determined; finally, the students were organized to sum up and discuss the experiment according to the experimental results.

The design of content-specified experiment was relatively simple and easier to do, it was easier for the teacher to control the process of experiment and to guide the students during the experiment, and the requirements for the hardware, class hour, teacher, and student level were not so high, 
suitable for all students who had received the education of junior college in medical colleges and universities.

Design of self-designed experiment. The self-designed experiment was divided into 5 steps as follows: (1) Raising questions for selecting an experimental topic. The key to the self-designed experiment was to raise the question. At the beginning of the term, the students were asked to prepare for the design of self-design experiment, including the discussion in groups to propose experimental topics with both innovativeness and feasibility; (2) According to the topic, the students were asked to refer to the relevant references and draw up the experimental programs, and then submitted them to the instructor for the check and modify the experimental programs. (3) Under the guidance of instructors, according to the experimental programs, the experimental operations were conducted first, then the experimental programs were constantly revised and improved during the experiments, and finally the experimental results were obtained. (4) The students were asked to analyze the experimental results, write papers, and give their presentations based on their experiments. (5) The teachers and the students assessed their experiments by evaluating their performance throughout their experiments.

Through the self-designed experiment, the students' subjective initiative could be given play to well, the students' abilities to find and solve problems should be built up and trained, and the students' potential innovation thinking and abilities might be induced. However, the self-designed experiment often requires more hardware facilities, experimental expenditure, experimental class hour and teachers, and also students with a more solid theoretical and experimental foundation, thereby more suitable for undergraduates or students who receive more high-level education in colleges and universities with better faculty and hardware conditions.

Questionnaire Survey of PBL method. After the end of the experiment course, the questionnaire survey of PBL in the experiment groups was carried out in the students and the results are shown in table 1. The results showed that most of the students believed that the application of PBL in the clinical pharmacology experiment could improve their learning methods; cultivate their innovative thinking, problem-posing, problem-analyzing and problem-solving capacity, and language expression and interpersonal communication capacity; not only strengthen their team assistance spirit, but also make the relationship between teachers and students more harmonious and the class atmosphere more active; improve their understanding on the experiment content and their experiment skills significantly, which should be most important.

Questionnaire of PBL method [ $\mathrm{n}(\%)]$

\begin{tabular}{llll}
\hline Items & Yes & So so & No \\
\hline Expanding in knowledge range and depth & 95 & 5 & 0 \\
Improvement in autonomous learning ability & 96 & 4 & 0 \\
Improvement in problem-analyzing and solving & 90 & 10 & 0 \\
Improvement in experimental skills & 92 & 8 & 0 \\
Improvement in scientific thinking & 98 & 2 & 0 \\
Improvement in language expression and interpersonal & 80 & 15 & 5 \\
communication & & & \\
Cultivation in cooperative awareness and team spirits & 80 & 15 & 5 \\
\hline
\end{tabular}

Discussion. With the progress of society and the improvement of living standards, the traditional medical services can not meet the patient's needs and people have required a higher standard and demand for medical healthcare services, a comprehensive and responsive service. The overall change from "treatment-centered" to "patient-centered" in medical healthcare services requires that clinical staff should improve their quality increasingly. The traditional model of medical education 
takes imparting knowledge as its main task and teachers are centered during the verification experiment teaching, in which students often learn passively and are apparently lack of an initiative, with a big disadvantage and unable to meet the demands of the time.

Based on the teaching thinking of "learning in the process of problem-solving ", PBL teaching mode can overcome the disadvantages of the traditional education in theory and practice, and closely combine the basic medical knowledge with clinical knowledge of medicine, to emphasize the acquisition, assessment and applied skills of medical information resources, which can effectively improve students' initiative to learn and participate, increase students' interest in learning, stimulate students' learning passion, cultivate students' learning attitude and skills, improve students' ability to analyze and solve problems, and contribute to the formation of students' personality and the cultivation of their innovative spirit. In addition, experiment courses are different from theory courses. In an experiment course, there are fewer students so that the students and teachers can communicate and exchange at any moment, and the experimental operation more requires teamwork, which may be an opportunity for students to practice their interpersonal skills ${ }^{[10-11]}$, providing favorable conditions for the implementation of PBL teaching.

The teaching with PBL is to discover and solve the problem. The problem is a prerequisite to arouse students' curiosity and also a premise of the students to understand and absorb the knowledge. Therefore, it is unnecessary for us strictly to follow methods used in high-level colleges and universities in western developed countries and in our country, and what is correct is to select different implementation programs according to our own conditions and students' circumstances for the reform and innovation. As long as we take every opportunity to ask students for a few more "why" or encourage them to ask "why", very good results can be achieved.

"To teach one how to fish rather that just giving one a fish", PBL teaching mode is a lifelong self-education mode. PBL can make students in a strong learning atmosphere, to fully mobilize their learning interest and enthusiasm, learn learning skills, cultivate a capacity to acquire new knowledge, and became a lifelong self-educator, which may contribute the real realization of the sustainable development in talents and also lay a solid foundation for becoming a qualified medical worker in the future.

\section{References}

[1]Wang Cong, Zhao Huiyuan.Reform on pharmacokinetic experiment teaching in clinical pharmacology courses [J]. China Medicine and Pharmacy, 2015, 5(21): 62-64.

[2]Wang Peng, Wu Guohua,Wang Tao,et al. Application of PBL teaching mode in the reform of pharmacological experiment teaching [J].Experimental Technology and Management, 2009, 26(3): 217-219.

[3]Lin Xiaoyin,Wei Ping,Tan Mingfe, et al. An applied study on problem based learning method in clinical Pharmacology [J]. North West Medical Education, 2008, 16(6):1158-1160.

[4] You Tingting, Chen Bo, Zou Liyi, et al. Reform and exploration of pharmacology experiment teaching for cultivating applied talents in pharmacy [J]. China Higher Medical Education, 2014(9): 55-56,117.

[5] Chen Lishu, Qu Zhongtang. Discussion on the reform of pharmacology experiment teaching mode [J].Modern Medicine \& Health, 2012, 28(3): 457-458. 